\title{
Case of Sister Mary Joseph's Nodule Inpatient Who Underwent A Whipple Procedure
}

\author{
Ana Lazarova*, Antonio Gligorievski and Ivan Nevcev
}

Department of Radiology, St.Kiril and Methodius, Medical faculty, University Clinic for surgery disease St.Naum Ohridski,Macedonia

ISSN: 2637-7632

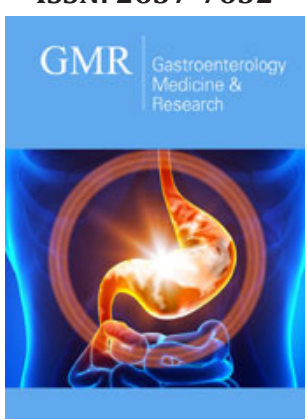

*Corresponding author: Ana Lazarova, Department of Radiology, St.Kiril and Methodius, Medical faculty, University Clinic for surgery disease St.Naum Ohridski,Macedonia

\section{Submission: 些 November 23, 2020}

Published: 眥December 16, 2020

Volume 5 - Issue 3

How to cite this article: Ana Lazarova, Antonio Gligorievski and Ivan Nevcev. Caseof Sister Mary Joseph's Nodule Inpatient Who Underwent A Whipple Procedure. Gastro Med Res. 5(3). GMR. 000613. 2020

DOI: $10.31031 /$ GMR.2020.05.000613

Copyright@ Ana Lazarova, This article is distributed under the terms of the Creative Commons Attribution 4.0 International License, which permits unrestricted use and redistribution provided that the original author and source are credited.

\begin{abstract}
Sister Mary Joseph's nodule (SMJN) is a metastatic malignancy of the umbilicus which indicates advanced, metastatic disease. Sister Mary Joseph nodule or Sister Mary Joseph Sign refers to a palpable nodule bulging into the umbilicus as a result of metastasis of cancer in the abdomen or the pelvis. It is a rare occurrence, but it is a sign of abdominal cancer, most commonly an adenocarcinoma metastasis from a gastrointestinal (gastric, colonic, pancreatic cancer) or gynecologic primary malignancy. We present the case of a 61-year-old man with an acute, something less than $1 \mathrm{~cm}$ in diameter non-tender mass located in the umbilicus, diagnostic indication of an SMJN. This patient, 4 months before was diagnosed with pancreatic carcinoma and underwent a Whipple procedure with pathophysiology result ofAdenocarcinoma capitis pancreatic pTNM $=$ pT2 pN1 pMX. This little nodal change in the umbilicus was an indication for further investigation so a computer tomography (CT) scan was done. Our findings are discussed in the following case report.
\end{abstract}

Keywords: Umbilical nodule;Metastatic cancer;Intra-abdominal cancer;Pancreatic cancer; Sister mary joseph nodule.

\section{Introduction}

Sister Mary Joseph's nodule (SMJN) is a rare growth found at the umbilicus that indicates a metastasis from an abdominal or pelvic source. Cutaneous metastases of malignant neoplasms are relatively uncommon, occurring between $0.7 \%$ and $9 \%$ of autopsy evaluations $[1,2]$. An SMJN typically presents as an umbilical nodule commonly less than $5 \mathrm{~cm}$ in diameter it ranges from 0.5 to $15 \mathrm{~cm}$ and may express bloody and purulent discharge [3]. The nodule has been described as white, bluish violet, and brownish-red and is occasionally pruritic (Figure1). It is usually irregular in shape, generally painless when palpated except if the overlying skin has ulcerated [4]. The most common origins of Sister Mary Joseph nodule are gastrointestinal (gastric, colonic, pancreatic cancer)-52\%, gynecologic (28\%), and ovarian (16\%) carcinomas. About $15-29 \%$ of all cases have an unknown origin (as depicted by the presented case) and 3\% originate from the thoracic cavity [5]. Primary tumors in many other sites like gall bladder, uterus, liver, endometrium, small intestine, fallopian tube, appendix, cervix, penis, prostate, urinary bladder, breast, lung, and kidneys have also been reported to cause Sister Mary Joseph nodules, but they are extremely rear [6,7]. Histology of the metastatic umbilical tumor usually reveals adenocarcinoma but rare reports of umbilical metastasis from sarcomas, mesotheliomas, and melanomas have also been seen [8]. The mechanism of spread of cancer to the umbilicus is not known for sure but proposed mechanisms include direct transperitoneal spread via lymphatic running along the obliterated umbilical vein, hematogenous spread, or via remnant structures like the falciform ligament, median umbilical ligament, or a remnant of the umbilical duct $[9,10]$. Gastrointestinal malignancies account for about half of the underlying sources (gastric, colonic, pancreatic cancer), gynecologic (ovarian, uterine cancer), unknown primary tumors and rarely bladder or respiratory malignancies cause umbilical metastasis [11].

Recognition of the nodule is of great importance because it may be the first presenting sign in a patient with a previously unknown malignant disease [12]. Sister Mary Joseph's nodule is uncommon, with an estimated $1-3 \%$ cases of abdominopelvic malignancy metastasizing to the umbilicus [13-15]. It is important to have in mind that Sister Mary Joseph's nodule may be the only presenting complaint in an otherwise well patient; other patients can present in a poor clinical state with additional physical signs such as ascites 
and pleural effusion [16,17]. The differential diagnosis that might be considered of a patient presenting with an umbilical nodule should include primary umbilical neoplasm, Sister Mary Joseph's nodule (metastatic umbilical nodule), umbilical hernia, umbilical endometriosis, omphalitis, keloid, pyoderma gangrenosum, and foreign body [18]. This umbilical nodule metastasis was named after Julia Dempsey (14 May 1856-29 March 1939), better known as Sister Mary Joseph, who was an American religious sister, nurse, and hospital administrator [15]. Sister Mary Joseph was trained by the only experienced nurse in the city and became the hospital's head nurse and surgical assistant to Dr. William J. Mayo, one of the Mayo brothers that founded the Mayo Clinic. Sister Mary Joseph remained his assistant until 1915. She became superintendent of the hospital in 1892 and remained in that role until 1939. She founded Saint Mary's Hospital Training School for Nurses in 1906 to help alleviate a shortage of nurses (Figure 2). She died on 29 March 1939 at Saint Mary's Hospital $[14,19]$. She drew attention to the presence of a hard umbilical nodule in a patient being prepared for surgery in 1928. Sir Hamilton Bailey coined the term "Sister Mary Joseph nodule" in the $11^{\text {th }}$ edition of his textbook "Demonstrations of Physical Signs in Clinical Surgery” in 1949 [15,20].
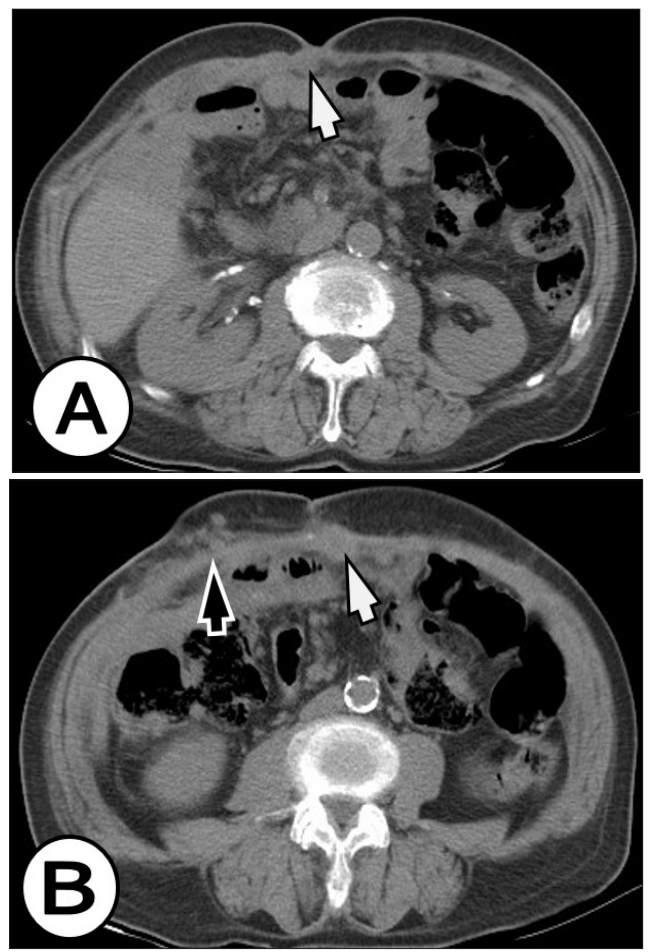

Figure 1: Axial MDCT without the intravenous contrast.

(A) CT scan showed a mass at the umbilicus, (white arrow).

(B) CT scan showed a Mary Joseph Sister nodule (white arrow), and a distal to the umbilicus on the right side several well-circumscribed nodules were seen lying within the subcutaneous tissue of the anterior abdominal wall (black arrow).
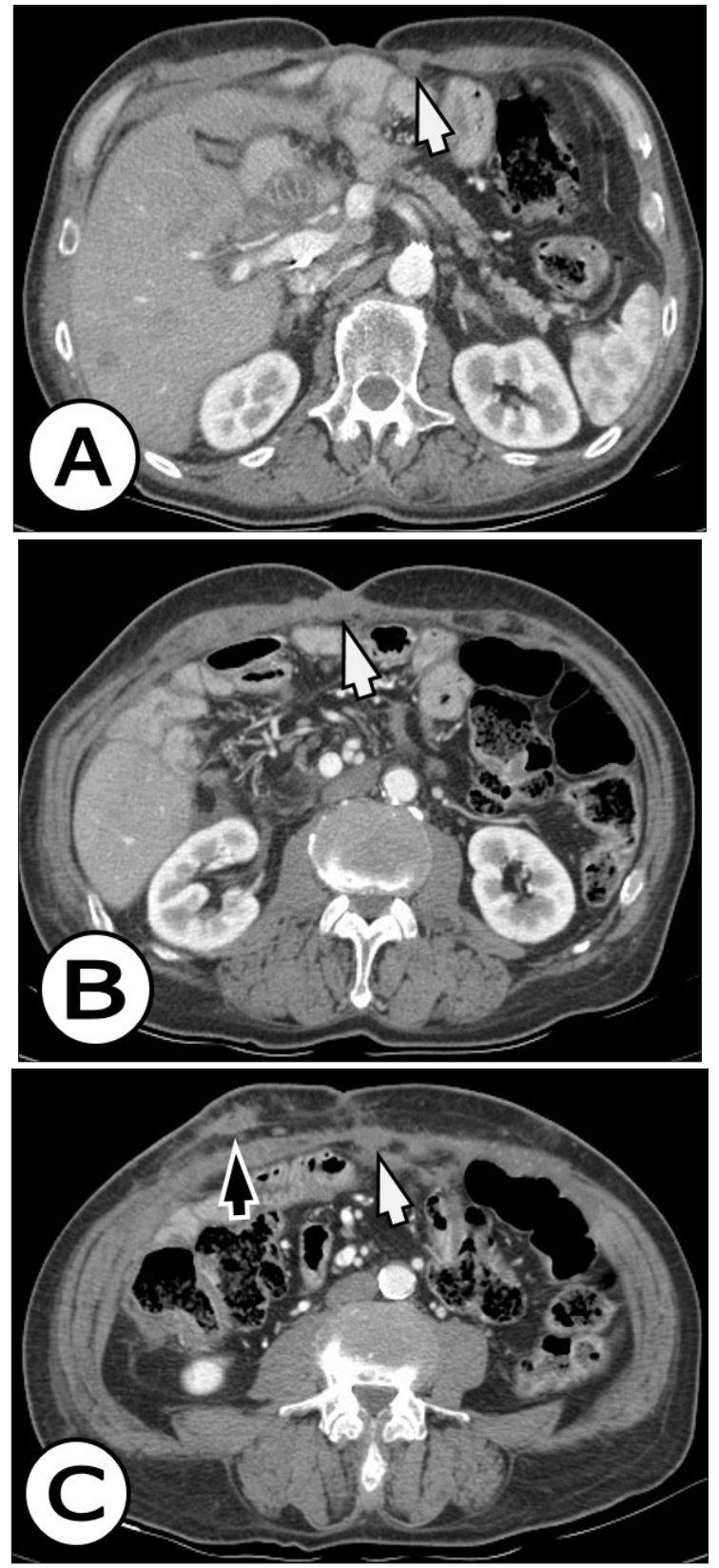

Figure 2A-2C: Contrast-enhanced MDCT axial slices in arterial phase: CT scan showed a Mary Joseph Sister enhanced nodule (white arrow), and a distal to the umbilicus on the right side several well-circumscribed enhancing nodules were seen lying within the subcutaneous tissue of the anterior abdominal wall (black arrow). There was no evidence of recurrence of the primary tumor.

\section{Case Report}

We present a case of 61 years old man who spotted a non-tender palpable mass into the umbilicus. This patient has a history of obstructive icterus as a result of tumor formation in the pancreatic head, which resulted in operative treatment-Laparotomic sec. Duodenopancreatectomia cephalic sec. Whipple, four months 
ago. Pathophysiology confirmed Adenocarcinoma capitis pancreatic (pTNM = pT2 pN1 pMX G2 L1V0). When a non-tender umbilical nodal, with irregular margins which were at around $1 \mathrm{~cm}$ in diameter was spotted, a possible diagnosis of Sister Mary Joseph's nodule was established, especially because the history of pancreatic adenocarcinoma is known. There was an indication for computer tomography-CT scan which confirmed the diagnosis and tumor mass in the paraumbilical region with a diameter of $25 \mathrm{~mm}$ was found. Also in the umbilicus, tumor mass was detected with a diameter of $20 \mathrm{~mm}$, both of them refer to metastatic nodule or SMJN. Also in the liver, there were few focal nodular lesions with a great diameter of $16 \mathrm{~mm}$ and localized free abdominal fluid-ascites around the remind part of the pancreas (part of the body and pancreatic tail) and also in the Morrison space (Figure 3).

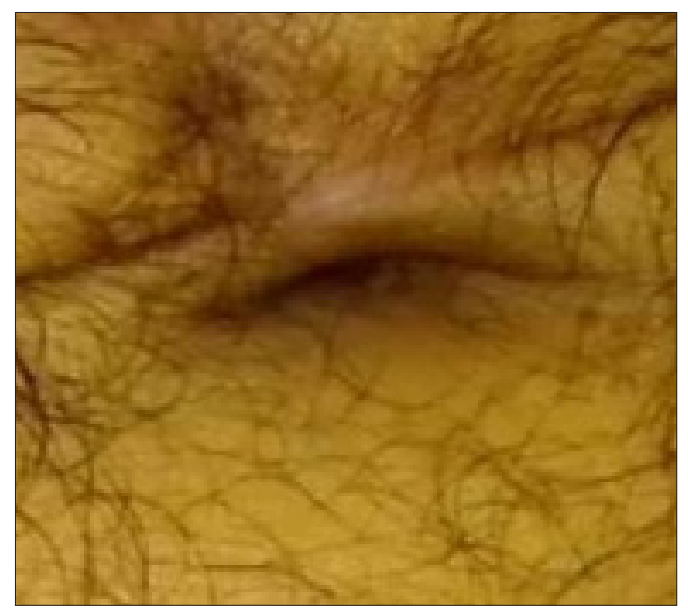

Figure 3: The picture shows a Mary Joseph Sister nodule in the umbilicus.

\section{Conclusion}

Umbilical masses in adults are rarely to be seen in everyday practice, so every physician must show great concern when dealing with umbilical lesions. As in this patient's case, an SMJN can be an important diagnostic and prognostic factor to consider receive after the primary operation and disseminating malignancy should be taken in the matter. Therefore, these nodules are always an indication for further investigation into the primary cause of the growth. Because patients who are presenting with Sister Mary Joseph's nodule are in the term of advanced malignancy they have generally poor prognosis. That is why adequate management of the disease should take into account patient preference, the clinical state of the patient, and the etiology of the primary malignancy. It is a matter of an individual case does palliative management may be the only option for some patients, whereas in carefully selected cases, patients may benefit from more aggressive treatment such as surgery, chemotherapy, and radiotherapy. With this case, we have shown that although Sister Mary Joseph's nodule is an uncommon finding it is also a very important physical finding. Sister Mary Joseph's nodule is a clinical sign that is emphasizing the importance of a careful physical examination of the abdomen. It remains an interesting and useful diagnostic tool in modern medicine.

\section{References}

1. Steck WD, Helwig EB (1965) Tumors of the umbilicus. Cancer 18(7): 907-915.

2. Larentzakis A, Theodorou D, Fili K, Manataki A, Bizimi V, Tibishrani M, et al. (2008) Sister mary joseph's nodule: Three case reports. Cases Journal 1(1): 182

3. Galvan VG (1998) Sister mary joseph's nodule. Ann Intern Med 128(5): 410.

4. Majumdar B, Wiskind AK, Croft BN, Dudley AG (1991) The Sister (Mary) Joseph nodule: Its significance in gynecology. Gynecol Oncol 40(2): 152159.

5. Srinivasan R, Ray R, Nijhawan R (1993) Metastatic cutaneous and subcutaneous deposits from internal carcinoma. An analysis of cases diagnosed by fine needle aspiration. Acta Cytol 37(6): 894-898.

6. Powell FC, Cooper AJ, Massa MC, Goellner JR, Su WP (1984) Sister mary joseph's nodule: A clinical and histologic study. J Am Acad Dermatol 10(4): 610-615.

7. Deb P, Rai RS, Rai R, Gupta E, Chander Y (2009) Sister mary joseph nodule as the presenting sign of disseminated prostate carcinoma. J Cancer Res Ther 5(2): 127-129.

8. Wroński M, Kluciński A, Krasnodębski IW (2014) Sister mary joseph nodule: A tip of an iceberg. J Ultrasound Med 33(3): 531-534.

9. Aich RK, Karim MR, Chakraborty B, Dasgupta S, Deb AR (2008) Sister mary joseph nodule. Ind J Med Pediatr Onc 29(2): 40-43.

10. Ross JE, Hill RB Jr (1975) Primary umbilical adenocarcinoma: A case report and review of literature. Arch Pathol 99(6): 327-329.

11. Bai XL, Zhang Q, Masood W, Masood N, Tang Y, et al. (2012) Sister mary joseph's nodule as a first sign of pancreatic cancer. World J Gastroenterol 18(45): 6686-6689.

12. Calongos G, Ogino M, Kinuta T, Hori M, Mori T (2016) Sister mary joseph nodule as a first manifestation of a metastatic ovarian cancer. Case Rep Obstet Gynecol 2016: 1087513.

13. Velasco MA, Garcia-Ureña, MA, Hidalgo M, Vega V, Carnero FJ (1999) Current concepts on adult umbilical hernia. Hernia 3: 233-239.

14. Ogilvie M, Joy H (2000) The biographical dictionary of women in science: Pioneering lives from ancient times to the mid- $20^{\text {th }}$ Century. New York, USA.

15. Urbano FL (2001) Sister joseph's nodule. Hospital Physician 37(5): 3335.

16. Victory R, Diamond MP, Johns A (2007) Villar's nodule: A case report and systematic literature review of endometriosis externa of the umbilicus. J Minim Invasive Gynecol 14(1): 23-32.

17. Al-Attar A, Mess S, Thomassen JM, Kauffman CL, Davison SP (2006) Keloid pathogenesis and treatment. Plast Reconstr Surg 117(1): 286300 .

18. Gabriele R, Conte M, Egidi F, Borghese M (2005) Umbilical metastases: current viewpoint. World J Surg Onc 3(1): 13.

19. Tso S, Brockley J, Recica H, Ilchyshyn A (2013) Sister mary joseph's nodule: an unusual but important physical finding characteristic of widespread internal malignancy. Br J Gen Pract 63(615): 551-552.

20. Salian S, Rodrigues G, Kumar S (2006) Sister mary joseph's nodule: An indicator of intraabdominal malignancy. Internet J Surg 10(2): 2.

For possible submissions Click below: 